\section{Estimating U.S. Consumers' Choice of Floral Retail Outlets}

\author{
Chengyan Yue ${ }^{1,3}$ \\ University of Minnesota-Twin Cities, Horticultural Science \& Applied \\ Economics, 1970 Folwell Avenue, St. Paul, MN 55108
}

\author{
Bridget K. Behe ${ }^{2}$ \\ Department of Horticulture, Michigan State University, East Lansing, MI \\ 48824
}

Additional index words. box store, demographics, direct-to-consumer, general retail, marketing, mass-merchandiser, traditional retail, floral outlets

\begin{abstract}
Competition among floral retailers has promulgated industrywide structural changes while giving consumers more choices in locations for purchase. Consumer panel data collected by the American Floral Endowment from 1992 to 2005 were used to evaluate consumers' choice of different floral retail outlets among box stores (BS), traditional freestanding floral outlets (TF), general retailer (GR), other stores (OS), and direct-to-consumer (DC) channels. Since 1992, market share and percentage of transactions decreased through TF but increased for BS. Mean expenditure per transaction in TF was higher than in BS and GR. Consumers who made floral gift purchases were more likely to patronize TF, but those who bought floral products for themselves were more likely to purchase from BS. Consumers patronizing TF or DC were more likely to buy arranged flowers rather than unarranged flowers. Consumers who purchased foliage plants and outdoor bedding or garden plants were more likely to buy them from BS. Reasons consumers who choose BS and GR cited for using those outlets included convenience and lower prices, whereas consumers who purchased from TF and DC cited delivery, reputation, and service as major drivers impacting their use. Demographic and geographic differences were also identified among consumers using the aforementioned outlets.
\end{abstract}

Production and marketing of ornamental plants are becoming increasingly important components of the U.S. agricultural sector. With a diverse set of retailers marketing floral products, competition is intensifying while channels of distribution are changing. Despite the growth of the ornamental plant market, the competition between traditional freestanding floral outlets (TR) such as garden centers and florists; general retail (GR) outlets, including supermarkets and department stores that sell floral products; box stores (BS) such as mass merchandisers and club centers; and direct-to-consumers (DC) outlets including Internet and telephone is becoming more intense. Other retail stores (OS) not characterized here such as street venders and farmer's markets are also marketing floral products.

Consumers choose different retail venues as a result of their own preferences and habits relative to the attributes of the retail venues, including available products and services. A

\footnotetext{
Received for publication 4 Dec. 2007. Accepted for publication 10 Jan. 2008.

The authors acknowledge American Floral Endowment's generous offer of the access to the Consumer Tracking Study data set.

${ }^{1}$ Assistant Professor and Bachman Endowed Chair in Horticultural Marketing.

${ }^{2}$ Professor.

${ }^{3}$ To whom reprint requests should be addressed; e-mail yuechy@umn.edu
}

better understanding of consumers' purchasing patterns and behavior and those key factors that affect consumers' choice can help retailers increase their sales in market share or price per transaction.

Some literature on consumers' preference for service and products related to landscape retailing at state and regional levels has been published. At the regional level, Brand and Leonard (2001) studied consumers' preference of plant attributes and choices between independent garden centers and mass merchandisers in New England. Behe and Barton (2000) investigated consumer perceptions of product and quality attributes of a variety of garden centers in six U.S. states (Alabama, Delaware, Kentucky, Tennessee, and Texas). Barton et al. (1998) published a review of the research related to consumers' preference in the nursery and landscape industry. Studies related to landscape retailing have been conducted in different states, including New Jersey (Baker, 1965), Arizona (Niemiera et al., 1992), California (Stamen et al., 1990), Kansas (Khatamian and Stevens, 1994), Georgia (Day, 1994), and North Carolina (Safley and Wohlgenant, 1995). Behe and Wolnick (1991) found that supermarket floral purchasers also infrequently made purchases from traditional retail florists; the consumer segments were discrete but overlapped somewhat. However, there is little insight on a national level with regard to consumer choice of floral retail outlets. This research is of great importance, because it helps fill this gap in the literature. In addition, this article differs from previous studies because it investigates multiple outlets to capture consumers' purchases in greater detail. There is also a longitudinal component, because panel data also allowed us to examine consumers' choice over time from 1992 to 2005.

\section{Materials and Methods}

Data used in this study were collected by the Ipsos-National Panel Diary Group (NPD) for the American Floral Endowment (AFE). NPD maintains an extensive consumer panel from which the AFE collected consumer transactions of floral products from 1992 to 2005. The data include consumers in 48 states and Washington, DC, and floral purchases were tracked monthly for 13 years. Altogether, there were 464,325 monetary transactions that were reported by the participants. Demographic information about participants, participant choices of retail outlets for each transaction, reasons why they chose certain retail outlets, whether the transaction was planned, who the consumers were buying for, and some other information, including flower color and type, were recorded. Given the 13year timeframe, large geographic area covered, and large sample size of the study, we consider the data representative of all consumers of floral products in the United States during this time period.

Consumers' choice of different retail venues is motivated by and depends on latent degree of satisfaction they can derive from the patronage (Greene, 2002). Consumers would like to choose the retailer who gave them the highest latent degree of satisfaction. Although satisfaction cannot be directly observed, their choice of specific floral retailer can. For this analysis, we grouped retail venues into five categories (Table 1): TR such as garden centers and florists, GR outlets, including supermarkets and department stores that sell floral products, BS such as mass merchandisers and club centers, and DC outlets, including Internet and telephone. DC was inherently different from other outlet types because it does not have a physical location, like a store, where consumers could make purchases. Other retail stores not characterized previously such as street venders and farmer's market were also included.

Because the dependent variable was categorical (five outlet types), we used a multinomial logit model to estimate the probability of a consumer's patronage of different stores. The consumers' satisfaction derived from patronage of different stores was related to certain measurable factors, including the consumers' characteristics, their preference for certain attributes of the retail outlets, the month and year of the purchase, whether they purchased for self-use or as gifts, and if they planned the purchase in advance. The consumers' characteristics included age, gender, education level, income, and household size. 
Table 1. Outlet categories and the corresponding retailers.

\begin{tabular}{|c|c|}
\hline$\overline{\text { Category }}$ & Retailers included \\
\hline $\begin{array}{l}\text { Traditional freestanding } \\
\text { floral retailers }\end{array}$ & Garden centers and florists \\
\hline Direct to consumer & Internet retailers ${ }^{\mathrm{z}}$, mail order, catalog, home/television shopping \\
\hline Box store & $\begin{array}{l}\text { Mass-merchandisers, warehouse club, home centers, } \\
\text { hardware stores }\end{array}$ \\
\hline General retailer & $\begin{array}{l}\text { Supermarkets, drug stores, convenience stores, department stores, } \\
\text { art/craft/hobby shops, and dollar/off-price stores }\end{array}$ \\
\hline Other & $\begin{array}{l}\text { Military/PX, street vender/cart, farmers' markets, nonprofit/fundraiser } \\
\text { and all other }\end{array}$ \\
\hline
\end{tabular}

${ }^{{ }^{2}}$ The tracking of Internet retailers started in 1998.

${ }^{\mathrm{y}}$ The tracking of dollar/off-price stores started in 2003.

All dependent explanatory variables and their summary statistics are listed in Table 2 .

The maximum likelihood estimation method was used to estimate coefficients using SAS 9.1.3 (SAS Institute, Cary, NC).
Of the 464,325 transactions, 435,613 observations were used for the analysis, or $93.8 \%$ of the data. The remaining observations were not used as a result of one or more missing values.

\section{Results and Discussion}

Of the 435,613 monetary transactions captured in the data set, $28.25 \%$ of them occurred in BS, $1.95 \%$ occurred in DC services, $29.20 \%$ at GR stores, $29.12 \%$ at $\mathrm{TF}$, and $11.48 \%$ at $\mathrm{OS}$.

Market share can be considered a metric of business financial success, which is measured as a percentage of industrywide sales. The percentage of sales is a combination of the number of transactions and the expenditure per transaction. Since 1992, the percentage of transactions occurring in the different types of retail venues has been changing (Fig. 1). The percentages of transactions in $\mathrm{TF}$ outlets and OS decreased over time, whereas the percentages of transactions at BS and GR outlets increased from 1992 to 2005. The percentage of transaction through

Table 2. Summary statistics for explanatory variables $(n=435,613)$.

\begin{tabular}{|c|c|c|c|}
\hline Variable & Description & Mean & SD \\
\hline \multicolumn{4}{|c|}{ Sociodemographics of consumers } \\
\hline Household & Household size (number of persons) & 2.842 & 1.301 \\
\hline Income $^{z}$ & Income level (1000 dollars) & 52.354 & 33.423 \\
\hline Age2539 & Age between 25 and 39 years, $1=$ yes and $0=$ no & 0.230 & 0.421 \\
\hline Age 4054 & Age between 40 and 54 years, $1=$ yes and $0=$ no & 0.370 & 0.483 \\
\hline Age 55over & Age 55 years and older, $1=$ yes and $0=$ no & 0.362 & 0.481 \\
\hline \multicolumn{4}{|l|}{ Quarter and year } \\
\hline Quater1 & First quarter, $1=$ yes, $0=$ no & 0.192 & 0.394 \\
\hline Quater2 & Second quarter, $1=$ yes, $0=$ no & 0.455 & 0.498 \\
\hline Quater3 & Third quarter, $1=$ yes, $0=$ no & 0.179 & 0.383 \\
\hline Quater4 & Fourth quarter, $1=$ yes, $0=$ no & 0.175 & 0.380 \\
\hline Year & $1=1992,2=1993, \ldots 14=2005$ & 8.065 & 3.874 \\
\hline GreenPlant & Green plants, $1=$ yes, $0=$ no & 0.074 & 0.262 \\
\hline FlowerHousePlant & Flowering house plant, $1=$ yes, $0=$ no & 0.132 & 0.338 \\
\hline OutdoorBed & Outdoor bedding or garden plants, $1=$ yes, $0=$ no & 0.436 & 0.496 \\
\hline ArtifDry & Artificial or dry flowers, $1=$ yes, $0=$ no & 0.102 & 0.302 \\
\hline \multicolumn{4}{|c|}{ The consumers choose the retail venue because of: } \\
\hline Convenience & Convenience of the store, $1=$ yes, $0=$ no & 0.302 & 0.459 \\
\hline Price & Price of the products in the store, $1=$ yes, $0=$ no & 0.255 & 0.436 \\
\hline Quality & Quality of the products in the store, $1=$ yes, $0=$ no & 0.137 & 0.344 \\
\hline Reputation & Reputation of the store, $1=$ yes, $0=$ no & 0.049 & 0.216 \\
\hline Service & Service of the store, $1=$ yes, $0=$ no & 0.010 & 0.099 \\
\hline Wireservice & Wire service of the store, $1=$ yes, $0=$ no & 0.005 & 0.071 \\
\hline Selection & Selection of the store, $1=$ yes, $0=$ no & 0.127 & 0.333 \\
\hline Delivery & Delivery service of the store, $1=$ yes, $0=$ no & 0.014 & 0.117 \\
\hline Other & Other reasons, $1=$ yes, $0=$ no & 0.100 & 0.300 \\
\hline MiddleAtlantic & New York, New Jersey, Pennsylvania, $1=$ yes, $0=$ no & 0.163 & 0.370 \\
\hline EastSouthCentral & Kentucky, Tennessee, Alabama, Mississippi, $1=$ yes, $0=$ no & 0.053 & 0.223 \\
\hline WestSouthCentral & Arkansas, Louisiana, Oklahoma, Texas, $1=$ yes, $0=$ no & 0.088 & 0.284 \\
\hline Mountain & $\begin{array}{l}\text { Montana, Wyoming, Colorado, Idaho, New Mexico, Nevada, Arizona, Utah, } \\
1=\text { yes, } 0=\text { no }\end{array}$ & 0.051 & 0.220 \\
\hline
\end{tabular}

${ }^{\mathrm{Z}}$ Income was in categories; midpoints of each category are used to generate a continuous variable. 
DC service was steady and started to increase in 2003.

The mean expenditure of each transaction in TF and DC outlets was higher than that of BS, GR, and OS between 1992 and 2005 (Fig. 2). Although the percentage of transactions in TF decreased, the mean expenditure per transaction in TF was higher than the mean expenditure in BS and GR. From both transactions and expenditure paid in each transaction, we calculated the approximate market share of different floral retail outlets over the years (Fig. 3). In Figure 3, market share for TF and OS decreased, whereas the market shares of BS and GR increased. Market share for DC was steady before 2000 and increased after 2000. Although the percentage of transactions in BS and GR was higher than the percentage in TF after 2001, the market share of TF is still the largest among the floral retail outlets.

Summary statistics and descriptions of the explanatory variables in the multinomial logit model are presented in Table 2. Nearly $81 \%$ of the shoppers were female; the mean household size of the shoppers was $\approx 3$ people; mean income level was $\approx \$ 52,000$; $4 \%$ of the shoppers were younger than age 25 years, $23 \%$ were between 25 and 39 years, $37 \%$ were between 40 and 54 years, and $36 \%$ were 55 years of age or older. Four percent graduated from grade school or finished some high school, $57 \%$ earned a high school degree or finished some college, and 39\% earned a college degree or have post college degrees. Most (45\%) floral purchases were made in the second quarter of the year, between April and June; $35 \%$ of the purchases were gifts and $70 \%$ of the purchases were planned ahead.

The estimation results using multinomial logit model are presented in Table 3 . The $P$ values for the likelihood ratio test and score test were all $<0.001$, which indicated a good fit of the model. The outlet category, OS, was used as the reference category. That is, the coefficients of variables for different outlet types in Table 3 are relative to OS (the coefficients of variables associated with OS set to zero).

Quarter and year. Monthly floral purchases influenced consumers' choice of floral outlets and these choices changed over the 13 years (Table 3 ). The variable year affected consumers' choice of outlets significantly. We observed that all the coefficients of year of different outlets were positive and significant. Compared with OS, consumers were more likely to choose the other four store types. When we examined the coefficient closer, we saw that the coefficient of year for BS was the largest. As the 13-year study progressed, the number of monetary transactions was likely to increase more rapidly in BS than GR, DC, and TF. GR was the second fastest growing floral outlet followed by DC. The percentage of transactions increased at the slowest speed at the TF. So, the likelihood of losing market share for TF is high, given the decline over the 13-year study timeframe. Most likely TF will lose share to BS and GR.



Fig. 1. Percentage of transactions occurring in different floral retail outlets from 1992 to 2005.

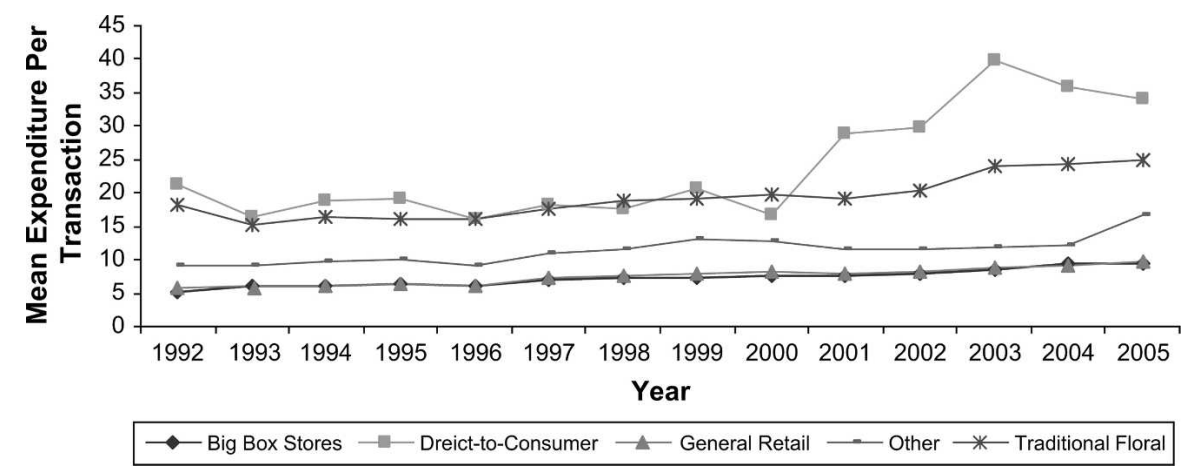

Fig. 2. Mean expenditure of individual transactions in different floral retail outlets from 1992 to 2005.

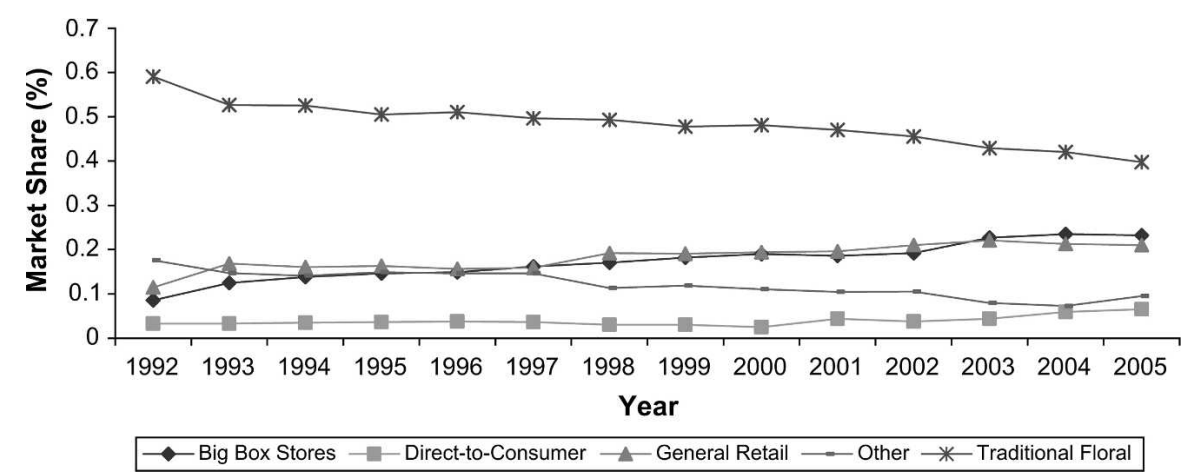

Fig. 3. Relative market share of different floral retail outlets from 1992 to 2005.

One plausible reason for this is that BS and GR have a greater or steadier flow of customers who pass by products other than floral outlets, thus exposing them to the floral product category more often. More frequent exposure of consumers to floral products may serve as a stimulus to impulse purchases. Compared with the fourth quarter of the year, consumers were more likely to choose DC outlets followed by GR and BS and they were least likely to choose TF during the first quarter of the year. In the second and third quarters, consumers tended to choose TF outlets rather than other outlets.

Region. Participants from different states were grouped into nine regions to make geographic comparisons, the classification of which was identical to U.S. census regions.
The regions included New England (Maine, New Hampshire, Vermont, Massachusetts, Rhode Island, and Connecticut), Pacific (Washington, Oregon, and California), east north central (Ohio, Indiana, Illinois, Michigan, and Wisconsin), west north central (Minnesota, Iowa, Missouri, Nebraska, Kansas, North Dakota, and South Dakota), south Atlantic (Maryland, Delaware, Washington DC, Virginia, West Virginia, North Carolina, South Carolina, Florida, and Georgia), middle Atlantic (New York, New Jersey, and Pennsylvania), east south central (Kentucky, Tennessee, Alabama, and Mississippi), west south central (Arkansas, Louisiana, Oklahoma, and Texas), and mountain region (Montana, Wyoming, Colorado, Idaho, New Mexico, Nevada, Arizona, and Utah). Results 
Table 3. Estimated coefficients for consumers' choice of retail floral outlets based on multinomial logit model $(\mathrm{n}=435,613)$.



***Significant at the $1 \%$ level; **significant at the $5 \%$ level; and *significant at $10 \%$ level.

showed that consumers in different regions were not homogeneous in their choices of floral retail outlets (Table 3). We used the mountain area as our base in the analysis. Results showed that consumers in the New England and the east north central areas were less likely to make a purchase from BS and GR compared with the other three types of outlets. Consumers in the Pacific region were more likely to choose OS and less likely to choose TF compared with other store types. They were also the consumers who were less likely to choose TF and DC outlets compared with consumers in other regions. Consumers in the west north central region were more likely to choose DC and TF and less likely to choose GR followed by BS. In addition, consumers in the west north central were most likely to choose TF compared with consumers in other regions. Consumers in the south Atlantic and the middle Atlantic were more likely to choose OS. Consumers in the middle Atlantic region were less likely to choose BS and GR compared with consumers in other regions. Consumers in the east south central were more likely to choose DC rather than other stores compared with consumers in other regions and they were less likely to choose GR compared with other store types. Consumers in the west south central were those who were more likely to choose BS than consumers in other regions. Consumers in the mountain area were more likely to choose GR compared with those in other regions (the coefficient is zero, whereas the coefficients for other regions were negative).

These geographic differences are possibly related to climate differences that enable various types of retailers to thrive in some areas (Pacific region) but not others (New England). For example, the high patronage of OS in the Pacific region may be somewhat attributed to year-round street vendors and outdoor markets that cannot exist year-round in other colder regions. Visibility of these vendors may be greater than $\mathrm{TF}$ in the same region, enticing consumers to make impulse purchases. Perhaps consumers in the east south central rely on DC rather than stores if they live in lower population-dense or more rural areas. These geographic differences do provide some retailers with an opportunity to develop a competitive advantage by understanding what marketing efforts are producing results (sales) in some regions, but not others. Is there a possibility of copying the success elsewhere? Knowing these regional differences exist provides the impetus for future investigation into causes for the differences.

Products purchased and use of products. Consumers who purchased floral products as gifts had a higher probability of patronizing $\mathrm{TF}$, but those who bought floral products for themselves were more likely purchase from a BS. Caplow (1984) reported that a primary motivation of gift givers is to fortify important relationships and maintain goodwill with gift recipients. A product perceived as cheap or inexpensive might not be able to fulfill the particular functions required by gifts; therefore, consumer are willing to pay more to buy products in TF to give as gifts. Our results are consistent with Huang (2007) who found that consumers emphasized price and longevity of flowers for self-use more than symbolic meaning and situational value of the floral products. Planned transactions were more likely to occur at TF and DC, whereas unplanned or impulse transactions were more likely to occur in GR, BS, and OS. This is somewhat intuitive because BS, GR, and OS 
sell items in addition to floral products. A consumer who planned to buy a loaf of bread might make an impulse purchase of a bouquet although he or she did not plan to buy any floral product. This kind of impulse purchase behavior may be less likely to happen in TF because of the specific and relatively narrow product line. Consumers may need a purpose for visiting the retailer. This finding has some implications for the choice of store locations of TF. Physically locating closer to other supermarkets or shopping outlets, TF might encourage consumers' impulse-buying behavior. Certainly, visibility of the store or floral outlet plays a role in increasing impulse transactions. Perhaps additional advertising and promotional efforts would encourage more consumers to patronize TF for impulse purchases.

We grouped floral products into six categories: arranged fresh cut flowers, unarranged cut flowers, foliage plants, flowering house plants, outdoor bedding or garden plants, and artificial and dried flowers. We used artificial and dried flowers as base category for the analysis. The large coefficients of all the fresh floral products for TF outlets compared with artificial and dry flowers indicates that TF had the highest likelihood for purchase of fresh floral products compared with other four outlets. When we compared the coefficients of the floral products within the TF outlets or DC outlets (vertically compare the coefficients in Table 3 ), we found that consumers who made purchases from $\mathrm{TF}$ or DC outlets were more likely to buy arranged flowers followed by outdoor bedding, garden plants, and flowering house plants rather than unarranged flowers. On the contrary, consumers who purchased from a BS were more likely to purchase foliage plants, outdoor bedding, and garden plants rather than fresh flowers. The finding is consistent with earlier finding by Day (1994). Consumers choose BS for familiar and lower-risk purchases and consumers who buy from a BS were least likely to buy arranged flowers.

Consumers who purchased from a GR were most likely to buy unarranged flowers followed by flowering house plants and least likely to buy arranged flowers besides artificial or dry flowers. Fresh floral products prices can be higher than artificial or dried floral products, and arranged flowers need labor input from design personnel, which can partly explain why the mean expenditure per transaction in TF or DC outlets were higher than that in BS and GR. (The mean expenditure for fresh floral products was \$11.91 per transaction, whereas the mean expenditure for artificial or dry floral products was $\$ 9.57$ per transaction. The $t$ test statistic was 86.67 $(P<0.01)$, which showed that the two means were significantly different.)

Sociodemographics. Consumer demographic characteristics significantly influenced store selection for floral purchases (Table 3). Compared with male consumers, female consumers were more likely to purchase from GR followed by BS, TF, and OS.
Female consumers did not differ significantly from male consumers in purchasing from DC. Consumers with larger household size were more likely to purchase from GR and BS than OS, TF, and DC outlets. Participants with college degrees or postcollege degrees were less likely to make a purchase from a GR and BS compared with those with less education. Wealthier consumers were more likely to choose TF stores than other outlets. From the data set we found that the mean expenditure per transaction at TF was $\$ 19.06$ compared with $\$ 10.73$ at OS, $\$ 7.59$ at BS, and $\$ 7.74$ at GR, which may partly explain why wealthier consumers tend to choose TF (Wealthier consumers can afford a higher priced item, which may carry more prestige. To see if this was the case, we estimated the mean price for bouquet/bunch and singlestem fresh cut flowers for which there were accurate volume measures in the data. We found that the mean price in traditional floral was $\$ 9.67$, which was higher than $\$ 5.73$ in box stores and $\$ 4.38$ in general retail.) This is also validated in the next section by the fact that reasons consumers choose BS and GR are partly because of the lower price. As income level decreased, consumers were more likely to choose OS, BS, DC, and GR. With a larger household size may come reduced per-capita income, making these findings more intuitive and consistent. With higher education may come increased income, also making those findings consistent with each other. It was possible that wealthier customers shop at traditional retail and bought more each time they shop, increasing the expenditure per transaction.

Consumers' age affected their choice of floral outlets. Compared with the older consumer ( 55 years or older), consumers younger than 25 years of age were more likely to use DC outlets than other types of outlets. This was true for the consumers between ages 25 and 39 years as well. In addition, consumers between 25 and 39 years of age were more likely to choose BS than the consumers who were 55 years of age or older. Consumers between ages 40 and 54 years did not differ from those who were older than them in their choice of BS and DC stores, but they were less likely to purchase from $\mathrm{TF}$ and GR compared with other store categories. Clearly, TF need to work harder to generate additional customer traffic, especially among younger potential customers.

Reasons for choosing different outlets. Participants were asked the reasons why they choose a certain outlet for each of their transactions. "Other" reasons were used as the reference category for this analysis. Consumers differed in their reasons for choosing different retail outlets. The consumers who choose BS and GR were more likely to cite convenience and low price. When we compared BS and GR, we found that consumers who choose BS ranked low price higher than convenience as the primary reasons, whereas the consumers who choose GR ranked convenience higher. This result is consistent with Day (1994) who found that price was the major reason why consumers choose mass merchandisers.

However, consumers who purchased from TF ranked delivery the highest followed by reputation, quality, and service, but they ranked price lowest. The findings are also consistent with the literature, which showed that quality was the top reason for the consumers who choose garden centers (Horticulture Research Institute, 1986; Khatamian and Stevens, 1994; Niemiera, Innis-Smith and Leda, 1992; Powell, 1994; Safley and Wohlgenant, 1995). TF were also the outlet for more gift purchases. There would be minimal need to deliver an arrangement for personal enjoyment, so it was likely most purchases from $T F$ were gifts that need to carry a higher prestige with delivery. This was because most people would not ask to deliver flowers to themselves for personal use. Gifts carry higher prestige for recipients by being delivered by professionals rather than by the gift givers.

As expected, consumers who choose DC outlets ranked delivery highest followed by wire service and reputation. They also ranked price lowest. Labor for service and delivery (wire delivery) of TF and DC can also explain why the mean spending in these two outlets was higher than that in BS and GR.

\section{Conclusion}

The entire ornamental plant industry is experiencing a transition that higher percentage of transactions occurred in box stores and general retail as a result of the ever-expanding reign of chain stores and mass merchandisers. The competition between independent garden retailers and florists, general retail, direct-to-consumer, and box stores such as Home Depot, K-Mart, Wal-Mart, and Lowe's, among others, for the home gardener's demand for floral products and related accessories has intensified. The percentage of transactions have been falling in TR and increasing in BS and GR, yet market share of TR is still the highest among others. Determining how to compete against each other and gain market share is perhaps the most important challenge that all the retail venues face. Understanding consumers' behavior and purchasing pattern is of great significance for retailers' market decision. The comprehensive consumer tracking study conducted by AFE allows us to thoroughly investigate U.S. consumers' patronage pattern of different retail venues.

Not surprisingly, we found that U.S. consumers' choices of retail venues differed across different regions. Some retailers may have a competitive advantage in some regions of the country that they may be able to copy or duplicate in other geographic areas. Consumers bought at BS and GR because of low price and convenience, whereas consumers chose TR and DC because of the delivery, service, reputation, and quality. Consumers were more likely to buy gifts from TF instead of BS. Wealthier consumers tend to patronize TF instead of BS. 
Our findings have important market implications. To some extent, consumers were actually buying "different" products from different outlets, which partly explains why the mean expenditure of products per transaction in $\mathrm{TF}$ and $\mathrm{DC}$ were higher than that in BS and GR; consumers who chose TF and DC not only bought the products themselves, but also the labor invested in designing and arranging flowers, serving specific needs of customers, and delivering; whereas consumers who bought at BS and GR might not consider themselves as enthusiastic gardeners because they bought on impulse and selected plants based on price. To maintain the market shares, it is important for the retailers to keep their market segments by differentiating products and service from each other.

Given the rapidly changing business environment, results discussed here should be a warning to many types of floral outlets to monitor market share and take steps to reduce attrition or enhance growth. Market size can be roughly calculated by multiplying the average number of transactions (Fig. 1) by the average expenditure per floral transaction (Fig. 2) by the household number of a particular geographic area. Market share could be roughly approximated by dividing the market size of that same geographic area by retail sales for a specific business. Market share can be lost by erosion in real price relative to inflation or by a reduction in transactions or a combination of the two. Monitoring market share is the first step to awareness, but awareness of market share does not affect changes. By knowing the product segments consumers would be likely to purchase at different types of outlets and the reasons why consumers patronized certain retailers, floral retailers need to adjust their marketing efforts to help ensure growth in transactions, market share, and profits. This article provides a benchmark or basis against which to compare market share changes of different product segments for diverse floral retailers.

\section{Literature Cited}

Baker, M.E. 1965. New Jersey consumers study on attributes and knowledge. Amer. Nurseryman 121:8-60.

Barton, S.S., J.R. Brooker, C.R. Hall, and S.C. Turner. 1998. Review of customer preference research in the nursery and landscape industry. J. Environ. Hort. 16:118-124.

Behe, B. and S. Barton. 2000. Consumer perceptions of product and service quality attributes in six U.S. states. J. Environ. Hort. 18:71-78.

Behe, B.K. and D.J. Wolnick. 1991. Market segmentation of Pennsylvania floral consumers by volume and primary retail outlet. HortScience 26:1328-1331.
Brand, M.H. and R.L. Leonard. 2001. Consumer product and service preferences related to landscape retailing. HortScience 36:11111116.

Caplow, T. 1984. Norm-enforcement without visible means: Christmas gift giving in Middletown. AJS 89:1306-1323.

Day, E. 1994. An exploratory study of garden center selection for landscape plants. J. Environ. Hort. 12:142-146.

Greene, W.H. 2002. Econometric analysis. 5th Ed. Prentice-Hall, Upper Saddle River, NJ.

Horticulture Research Institute. 1986. Nursery consumer profile: Research summary. Horticulture Research Institute, Washington, DC.

Huang, L.C. 2007. Behavioral differences in prepurchase processes between purchasers of flowers for self use and for gift use. HortTechnology 17:183-190.

Khatamian, H. and A. Stevens. 1994. Consumer marketing preferences for nursery stock. J. Environ. Hort. 12:47-50.

Niemiera, A.X., J. Innis-Smith, and C.E. Leda 1992. Survey of garden center costumer informational needs. J. Environ. Hort. 11:25-27.

Powell, R. 1994. Knowing what is important to customers helps attract them. Green Business Reporter 6:1.

Safley, C.D. and M.K. Wohlgenant. 1995. Factors influencing consumers' selection of garden centers. J Agribusiness 13:33-50.

Stamen, T., J. Chambers, and J. Mamer. 1990 Marketing study of California lawn and garden consumers, p. 1-21. Univ. of Calif. Coop. Ext. Pub. 